Singh, A.R. and Delhi, V.S.K. (2018). "Site Layout Planning Waste Typology and its Handling Through AR-BIM Concept: A Lean Approach". In: Proc. $26^{\text {th }}$ Annual Conference of the International. Group for Lean Construction (IGLC), González, V.A. (ed.), Chennai, India, pp.123-133. DOI: doi.org/10.24928/2018/0475. Available at: www.iglc.net.

\title{
'SITE LAYOUT PLANNING WASTE' TYPOLOGY AND ITS HANDLING THROUGH AR-BIM CONCEPT: A LEAN APPROACH
}

\author{
Abhishek Raj Singh ${ }^{1}$ and Venkata Santosh Kumar Delhi
}

\begin{abstract}
Site layout planning (SLP) aims at the efficient placement of temporary facilities on a construction site. Improper planning can lead to tremendous wastes in terms of unnecessary transport of materials and other resources around the site. A plethora of research has presented SLP as an optimization problem, but a few have focused on the wastes involved and that occur due to an improper layout of the construction site. To develop the 'SLP waste' typology, a comprehensive literature review was done, and the experts of SLP were interviewed. The identified wastes were found to be resulting due to inefficient layouts, improper coordination and collaboration among the project stakeholders and conflict of their interest. The interviewed experts highlighted the inefficiency of two-dimensional (2D) drawings and requirement of three-dimensional (3D) visualization that can aid in envisioning the future site scenarios. Therefore, utilizing Augmented Reality (AR) integrated Building Information Modeling (BIM), a conceptual tool 'AR-BIM' is proposed, and the anticipated working is briefed out in this study. The tool is under development and is expected to ease out the planning of site layouts and will aid in enabling lean, along with value generation in construction projects.
\end{abstract}

\section{KEYWORDS}

Lean Construction Sites, Site Layout Planning, Team Collaboration, Waste Elimination

\section{INTRODUCTION}

Lean construction is applied to minimize waste, with a motive towards value creation, and addressing the end user requirement (Aziz and Hafez 2013). In construction, "Waste" is defined as any deviation from the absolute minimum in terms of labour, equipment and material required for creating a product (Alarcon 1997). The paradigm of 'Lean Construction' is now being adopted across the world (Song and Liang 2011). The basic premise of lean philosophy is to enable stronger collaboration and coordination among

1 Ph.D. Scholar, Department of Civil Engineering, Indian Institute of Technology Bombay, India, arsingh@iitb.ac.in

2 Assistant Professor, Department of Civil Engineering, Indian Institute of Technology Bombay, India, venkatad@iitb.ac.in 
the project participants to streamline the construction process flows. Construction site layout planning (SLP) pulls in project stakeholders to plan and fix the location, shape and size of the temporary facilities required. Consensus on the decisions towards SLP is achieved utilizing two-dimensional (2D) drawings. These 2D drawings lack the three dimensional (3D) spatial constraints, due to which the wastes are generated. SLP is a decision-making process that calls for better visualization, coordination and collaboration so that an efficient layout can be prepared. Emerging technologies like Building Information Modeling (BIM), Computer Simulations (CS) and Augmented Reality (AR) promise better coordination and collaboration among project stakeholders. The applicability of the technologies mentioned above has been explored in all phases of the project, individually and in integration with one another (Zhao 2017). There exists research in the domain of Building Information Modeling (Sacks et al. 2010a), Simulation (Marzouk et al. 2011) and Visualization (Sacks et al. 2007) in conjunction to the lean construction, but the applicability of these technologies for site layout planning is understudied. The present research understands how the visualization of the process helps in adoption and implementation of lean (Rischmoller et al. 2006) and can aid better coordination and collaboration among the project stakeholders by enhancing the process transparency (Song and Liang 2011). Thus, this paper presents a conceptual tool and highlights its applicability for making lean site layouts by bringing leanness to the process of SLP.

\section{LITERATURE REVIEW}

\section{WASTES DUE TO FAULTY SITE LAYOUT PLANNING (SLP)}

Time and cost are major project evaluating parameters in the traditional model of measuring project performance. Alarcon (1997) suggested 'Effectiveness, Efficiency, Quality, Productivity, Quality of work life, Innovation and Profitability' as seven performance elements. The study also highlighted the controllable wastes in three categories of wastes. The study of the Brazilian construction sites by Formoso et al. (1999) brought up 8 major classification of wastes as (1) Overproduction, (2) Substitution, (3) Waiting Time, (4) Transportation, (5) Processing, (6) Inventories, (7) Movement, (8) Production of defective products. The losses due to the inadequate planning of stocks and locations of storage may lead to vandalism, material waste by deterioration, burglary, and robbery that results in monetary loss and such wastes can be attributed to the class of 'Inventories'. The wastes mentioned above, are also considered in research conducted by Osmani et al. (2008). A study of Abu Dhabi construction industry presented 27 construction wastes. The author Al-Aomar (2012) was able to classify the identified wastes into 7 categories. The wastes identified by researchers indicate that proper planning of site space can resolve and eliminate the wastes at the planning for site layout. Therefore, the following section highlights research conducted in the domain of site layout planning. 


\section{SITE LAYOUT PLANNING}

Ballard and Koskela (2011) presented construction project as "a product development process, though not necessarily of a product the design of which will be copied multiple times." The site development involves many decision-making steps related to size, shape, location, and duration of temporary facilities (TFs) on the construction site (Zolfagharian and Irizarry 2014). Researchers have defined the task as an optimization problem, but the sub-optimal decisions related to the TFs can result in losses or wastes. The research in this domain emphasizes more on finding the algorithm based solution to the problem resulting out an optimal solution to the planners. Sadeghpour and Andayesh (2015) have indicated that advancements in the field of automation and visualization as a potential area for the researchers to investigate. Studies conducted in the last decade depicts a shift in concern from time, cost, and quality to safety, productivity and efficiency on project sites. Pérez et al. (2016) reported the use of BIM technology to plan logistics and workspace on sites as fairly limited. The planning of site layout is considered to be a combinatorial task where project stakeholders require collaboration and coordination among and across teams for decision making.

\section{BUILDING INFORMATION MODELING (BIM) FOR LEAN CONSTRUCTION}

The implementation of BIM has shown a reduction of wastes involved in design development, the generation of project documents and coordination documents (Kumar and Mukherjee 2009). Sacks et al. (2010b) explored the synergy between lean construction and BIM by supporting planning and day-to-day construction control on sites utilizing KanBIM. The implementation of such BIM-based lean construction management system supports human decision making, negotiation among stakeholders, and granularity of planning on a daily level. The study by Liu et al. (2011) explored the potential of BIM systems to minimize construction waste. Liu et al. (2015) presented a framework for waste minimization utilizing BIM by reducing conflicts, rework, and errors.

\section{IMPLEMENTATION OF LEAN THINKING THROUGH VISUALIZATION}

The visual management has been considered as, one among the most important methodologies of attaining lean production (Koskela 1997). The criteria for assessment of a visualization tool, to support lean construction provided parameters like; continuous improvement, knowledge communication, and the relation with other tools. The use of computer-aided visualization can benefit planning of projects, monitoring and recording performance benchmarks, an increase of workflow, and release of bottlenecks. The major focus has been on visualization aspects of BIM but to visualize the workflow, 4D BIM, 4D CAD and other technologies like augmented reality can be utilized. VisiLean, a tool for providing lean production management had been proposed to provide clear visualization of workflow along with simplifying the implementation of BIM on construction projects (Dave et al. 2011). The presented research is undertaken to understand the impact of tools like AR and BIM in waste minimization process. 


\section{RESEARCH METHOD}

The study adopts a qualitative approach through expert interviews to achieve the above objective. To identify the themes to be discussed with the experts a comprehensive literature survey was done. The keywords used for searching the literary content were 'Lean Construction,' 'Waste Minimization', 'Site Layout Planning', 'BIM', 'Visualization', 'Augmented Reality' and the combination of the terms was also tried out. The wastes that generate due to faulty site layout planning were identified from the literature and expert interviews, were classified into two major categories as identifiable and unidentifiable to the layout planners. A semi-structured open-ended interview on the adoption of BIM and Lean and potential of BIM and AR in Lean was conducted with 15 experts. The interview data were analyzed utilizing the method highlighted by Appleton (1995). The following section provides detail of the authors' interaction with the construction industry experts and highlights the requirement of a visualization tool for enabling lean since from the layout planning stage of the project. The findings also provide an idea of how visualization can help stakeholders in identifying wastes and eliminating them.

\section{RESEARCH FINDINGS}

\section{WASTES FOR THE CONSTRUCTION INDUSTRY AND ELIMINATION STRATEGY}

Waste on construction sites is considered to be the waste only if it is visible and easily identifiable. The construction industry experts irrespective of experience, when asked about the wastes on the construction site promptly indicated material wastage. The following reasons were brought up for the wastes, generating on construction sites:

\section{Wastes Due to Rework}

Every respondent emphasized this category of waste. The construction site rework generates a huge amount of waste that is very hard to handle. The rework generates enormous debris on construction sites, which needs to be cleaned from the execution site. This waste not only results in the material wastage but also results in the wastage of manhours and money.

\section{Eliminating Rework}

The respondents underlined proper designing and contract documents can eliminate the rework. According to the interviewees, the designs of the project should be readily available, and no last-minute change should occur. This requirement of the experts corresponds to the traditional construction practice.

\section{Overproduction and Over Procurement of Material}

The interviewees reported major materials required on construction sites are steel and concrete. The requirement of concrete is calculated on a daily basis and is provided to the batching plant on the day of requirement. If the concrete is produced on site, the wastage of concrete was considered under overproduction, and if it is procured from some 
concrete supplier, it is categorized as over procurement. The same procurement categorization was reported for the steel.

\section{Eliminating the Over-Production and Excess Procurement}

The researchers in the past have mentioned the utilization of technologies like BIM for quantity take-off. The quantity take-off tools, work based on the level of details to which the three dimensional model of the project conforms. As measures for reducing wastage due to excess procurement and production, the experts highlighted the tolerance, within which the waste generation is not considered alarming for the project and hence is not given much concern. The interviews resulted out that these tolerances vary from project to project and process to process. To the authors, defining of tolerance does not seem to be an approach for waste elimination, and no way close to the lean practices for the construction.

\section{Waste Due to Offcut}

The industry experts listed out this wastage as the cutout pieces of the material like steel bars, timber, marble, and tiles. The reason attributed to these wastes is the improper detailing in the design and unskilled workers. These wastes are sometimes utilized on the construction sites and therefore are of no major concern in accordance with the interviewees' response.

\section{Elimination of the Cutouts}

Since the construction industry utilizes this waste on the project, this does not imply that its elimination should not be targeted. The existing technologies like precast and prefab can eliminate these wastes from construction sites. The pre-engineered components will eliminate the waste of scrap material, but is likely to generate the following waste.

\section{Waste Due to Improper Storage}

The experts reported this wastage in reference to the improper storage of materials and pre-engineered components. The material storage wastage was reported as a result of bad inventories and poor storekeeping. An unorganized way of stacking the pre-engineered components lead to huge monetary loss, due to deformation of the components.

\section{Elimination of Waste Due to Improper Storage}

The experts indicated the proper storekeeping, along with employment of Radio Frequency Identification (RFID) tagging system helpful in eliminating the wastage due to improper storage. Hence, the techniques mentioned above can aid in eliminating the occurrence of waste to a certain extent if employed appropriately.

\section{IMPROPER SLP WASTES AND WASTES IN THE SLP PROCESS}

The past researches have focused and indicated the reasons and the eliminatory or diminution measures for the wastes mentioned above, but the count focusing on the wastes involved in the processes like designing and planning, employed for aiding construction is relatively low to assist the construction industry in eliminating the process wastes. The succeeding section will provide comprehensive knowledge on the wastes due to faulty site layout planning and the wastes involved in the process of SLP. 


\section{Waste of Excessive Handling}

The waste results out due to the improper planning of the location of the storage facility and the location of material consumption. The experts highlighted the negligence of the team responsible for planning and the team in charge of the storage for this wastage. One of the respondents highlighted the responsibility of the storekeeping team stating that: "If the material on construction site is not unloaded at the designated location then the team responsible for the storage should be held responsible for the waste of time and cost to be incurred in shifting the material as well as for the locked up space due to unloading at an inappropriate location."

\section{Unnecessary Movement}

This referred to the unrequired movements of vehicles and labours. The industry expert attributed this waste to the improper planning of site layout depicting: "The location of labor huts and routes on construction sites are a job for the planning team to carry out before the execution on construction site starts."

\section{Blocked Space}

The blockage of construction site happens due to improper envisaging of the future scenarios by the planning team and the poor housekeeping of the site. While interviewing the waste of space was highlighted by maximum respondents, and their response is summarized here: 'Construction site planning happens as soon as the contract is awarded based upon the prevailing geographic conditions and the provided area for the coming up facility. In a hurry to start the execution, the planning of SLP is not given proper concern, and as a result, as the construction progresses, the site becomes a fouled up place. The major mess is due to improper housekeeping resulting in space blockages on site.'

\section{Inefficient Coordination and Collaboration}

The process of SLP is considered to be a teams' task majorly deciding upon the location of facilities required to aid the main construction. The team comprises of stakeholders from different field of expertise like project manager, site supervisor, site engineer and sub-contractors. The task is accomplished by collaborating using 2D drawings as a mode of information share. Since few studies have highlighted the inefficacy of the drawings (Cheng and O'Connor 1996) sometimes, this results in the waste of discussion utilizing $2 \mathrm{D}$ drawings and results in a waste due to inefficient coordination and collaboration.

\section{Typology of Wastes and Possible Approach for its Minimization}

The wastes reported by the interviewees were the resulting wastes due to the improper layout of the site and also the wastes that exist in the process of SLP. Based upon the responses the SLP wastes are classified below. 


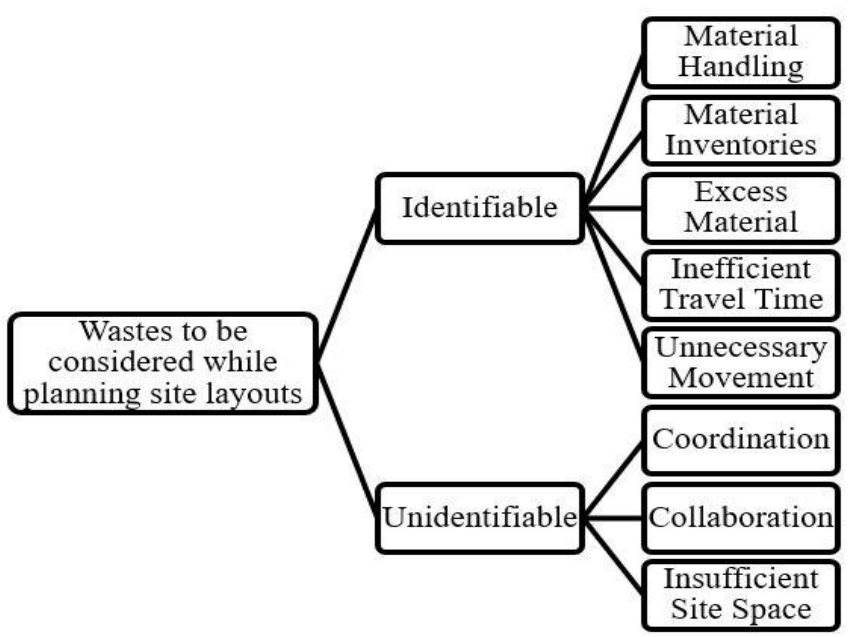

Figure 1: Categories of wastes considered while SLP

Figure 1 depicts the wastes which are anticipated by the stakeholders while planning for site layout. The identifiable wastes are easy to figure out and are considered during layout planning but since the wastes listed down in the unidentifiable category are hidden wastes of the process, which are left unnoticed.

The interviewed experts highlighted a pressing need to have some tool which can make the decision-making task easier and can aid the planners in eliminating the identifiable and unidentifiable wastes. The respondents highlighted the requirement of such tool as: 'The task of site layout planning is essential to be executed properly. It can be considered to be the foundation task of the project and if not accomplished in a righteous manner then can result out huge wastes on site. There would be a loss of worker's productivity, equipment productivity, and materials. Therefore, a tool is required through which all possible alternatives can be evaluated through permutation and combinations and all the solutions can be made clear to all the stakeholders involved in the task.' To this end, the authors have considered the developed typology and have come up with an approach to tackle the unidentifiable wastes involved in the process of SLP.

\section{CONCEPTUAL TOOL FOR SITE LAYOUT PLANNING}

The developed typology indicates the coordination and collaboration among project stakeholders as unidentifiable wastes involved in the process of SLP and the identifiable wastes are resultant of an inefficient SLP process. Thus, the authors hypothesize that addressing of the unidentified wastes in SLP can eliminate the wastes generated as result of the process. The planning for layouts of the construction site requires envisaging the future scenarios and making decisions based on the desired objectives. The study by Cheng and O'Connor (1996) reported the task is a job for stakeholders with expertise and have own concerns and interests in locating the support facilities. The deficiency of 2D drawings and the dynamic nature of construction site, motivated the authors to propose a conceptual tool that can aid the stakeholders, in enabling a better platform to collaborate and coordinate. The tool is defined and proposed to mitigate the wastes in the process of 
planning site layouts and the resultant wastes due to the improper planning of layout. The technologies like Building Information Modeling have proved its potential in 3D visualization and Augmented Reality for establishing collaboration in teams can be employed for the tool. The unification of these technologies will result out an innovative tool AR-BIM, for collaborating and visualization simultaneously. It is anticipated that the merger of the technologies should not restructure the whole process of site layout planning and therefore the tool would be an aid for value generation. The construction industry has adopted the BIM and AR for the construction progress monitoring (CPM) and facility management (FM). Therefore, the proposed tool is also expected to achieve leanness at the project planning phase.

\section{EXPECTED PERFORMANCE OF THE TOOL PROPOSED}

The proposed AR-BIM tool is expected to enable coordination and collaboration among the project stakeholders involved in the process of SLP. The proposed tool is in the development phase, and thus the working presented here is an anticipation. The tool will help in 3D visualization of the site scenarios by superimposition of the digital model on the real world, utilizing the basic functionality of augmented reality. The tool will enrich the site drawings with the 3D spatial information as depicted in figure 2 when brought in its field of view.

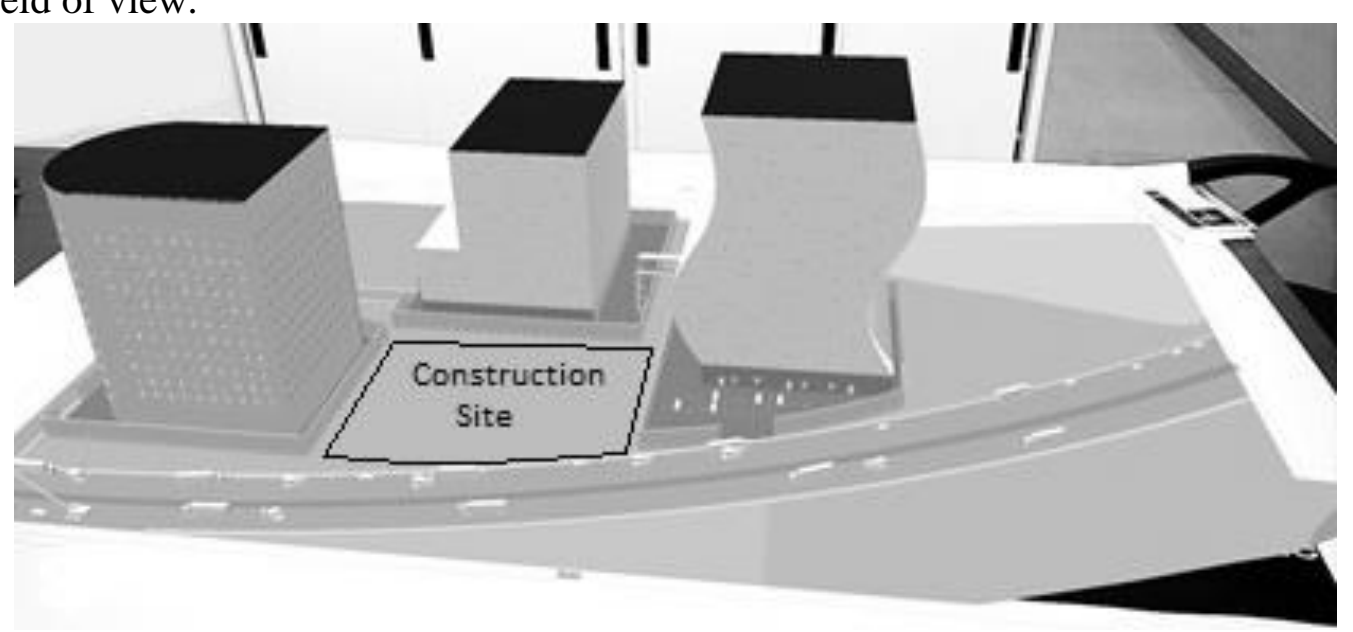

Figure 2: Visualization of site features through AR-BIM tool

When the stakeholders will get involved in the decision making task of SLP, the visibility of features like site access, terrain and site surroundings will come to fore and aid in the SLP process. The adoption of BIM technology for the conceptual tool will aid the stakeholders from different trades to collaborate; utilizing a common information model which will enable resolution of conflicts and will bring the process transparency. The integration of AR and BIM will help out in planning for site layouts by superimposing the BIM models of the site and the required TFs over the $2 \mathrm{D}$ drawings using the fiduciary marker technique for target tracking as shown in figure 3 . 


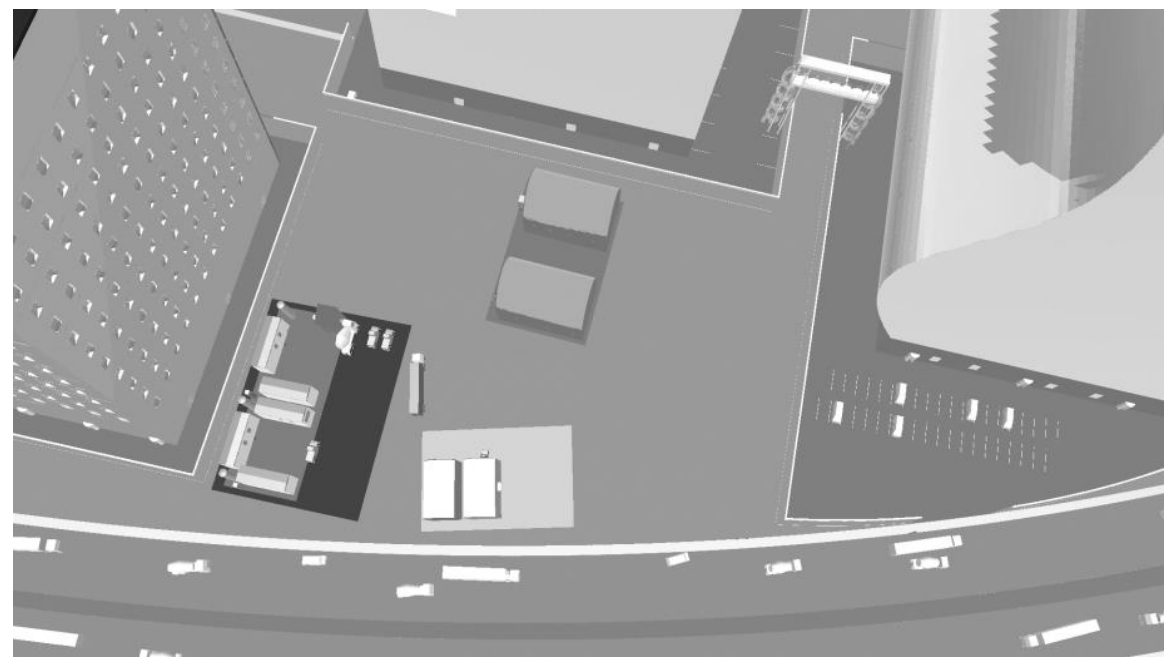

Figure 3: Rendering of TFs on the construction site

The AR-BIM tool would be handy for the end users, such that it will not restrict the movement of the stakeholders involved in the SLP task. The flexibility of moving around the visualized 3D model in the augmented environment will aid in utilizing the spatial information available in the BIM model. The tool is also expected to enhance the big room concept involved in the lean construction by eliminating the delays in decision making and improving the trust among the stakeholders involved in SLP.

\section{LIMITATIONS OF THE RESEARCH}

The aim of the study is not to generalize the findings; however, since the study surveyed top construction companies and experts, the findings were consistent and thus some inferences had been made. The study is also limited to examining the site layout planning; further study can incorporate other processes of the project. Notably, the outcomes in this study are on the results of the conversation with the construction industry experts. There is an earnest need to do the case study based research which also can ensure the applicability and effectiveness of the proposed tool.

\section{CONCLUSION}

The study was conducted to understand the construction sites' wastes and the wastes resulting due to bad site layout planning. The approach was constituted such that the process of site layout can be made lean by eliminating the wastes involved in the process of SLP and the wastages due to the improper planning of site layout. The experts' interview helped in identification of the anticipated wastes by the planners as well as the wastes that remain unnoticed. To this end, it is a preliminary study concerning the waste of inefficient SLP, and a conceptual tool is proposed. The proposed AR-BIM tool is an integrated result of the visualization technology and a collaborative tool. The applicability and adaptability of the proposed tool remain questionable and provides the future scope of research. 


\section{REFERENCES}

Al-Aomar, R. (2012). "Analysis of Lean Construction Practices at Abu Dhabi Construction Industry." Lean Construction Journal, 105-121.

Alarcon, L. F. (1997). "Tools for the Identification and Reduction of Waste in Construction Projects." Lean construction, L. F. Alarcon, ed., 365-377.

Appleton, J. V. (1995). "Analysing qualitative interview data: addressing issues of validity and reliability." Journal of Advanced Nursing, 22, 993-997.

Aziz, R., and Hafez, S. (2013). "Applying lean thinking in construction and performance improvement.” Alexandria Engineering Journal, 52, 679-695.

Ballard, G., and Koskela, L. (2011). "A Response to Critics of Lean Construction." Lean Construction Journal, 13-22.

Cheng, M. Y., and O'Connor, J. T. (1996). “ArcSite: Enhanced GIS for Construction Site Layout." Journal of Construction Engineering and Management, 122, 329-336.

Dave, B., Boddy, S., and Koskela, L. (2011). "VisiLean: Designing a Production Management System with Lean and BIM." 19th Annual Conference of the International Group for Lean Construction, Peru, 514-524.

Formoso, C. T., Isatto, E. L., and Hirota, E. H. (1999). "Method for Waste Control in the Building Industry." 7th Annual Conference of the International Group for Lean Construction, California, 325-334.

Koskela, L. (1997). "Lean Production in Construction.” Lean Construction, L. F. Alarcon, ed., 1-8.

Kumar, J. V., and Mukherjee, M. (2009). "Scope of Building Information Modeling (BIM) in India." Journal of Engineering Science and Technology Review, 2, 165-169.

Liu, Z., Osmani, M., Demian, P., and Baldwin, A. (2015). "A BIM-Aided Construction Waste Minimisation Framework." Automation in Construction, 59, 1-23.

Liu, Z., Osmani, M., Demian, P., and Baldwin, A. N. (2011). "The Potential Use of BIM to Aid Construction Waste Minimisation." Proceedings of the CIB W78-W102, France, $1-10$.

Marzouk, M., Bakry, I., and El-said, M. (2011). "Application of Lean Principles To Design Process in Construction Consultancy Firms." International Journal of Construction Supply Chain Management, 1, 43-55.

Osmani, M., Glass, J., and Price, A. D. F. (2008). "Architects' Perspectives on Construction Waste Reduction by Design.” Waste Management, 28, 1147-1158.

Pérez, C. T., Fernandes, L. L. A., and Costa, D. B. (2016). "A literature review on 4D BIM for logistics operations and workspace management." 24th Annual Conference of the International Group for Lean Construction, Boston, 53-62.

Rischmoller, L., Alarcón, L. F., and Koskela, L. (2006). "Improving Value Generation in the Design Process of Industrial Projects Using CAVT." Journal of Management in Engineering, 22, 52-60.

Sacks, R., Esquenazi, A., and Goldin, M. (2007). "LEAPCON: Simulation of Lean Construction of High-Rise Apartment Buildings." Journal of Construction Engineering and Management, 133, 529-539. 
Sacks, R., Koskela, L., Dave, B. A., and Owen, R. (2010a). "Interaction of Lean and Building Information Modeling in Construction." Journal of Construction Engineering and Management, 136, 968-980.

Sacks, R., Radosavljevic, M., and Barak, R. (2010b). "Requirements for Building Information Modeling Based Lean Production Management Systems for Construction." Automation in Construction, 19, 641-655.

Sadeghpour, F., and Andayesh, M. (2015). "The Constructs of Site Layout Modeling : An Overview." Canadian Journal of Civil Engineering, 42, 199-212.

Song, L., and Liang, D. (2011). "Lean Construction Implementation and its Implication on Sustainability: A Contractor's Case Study." Canadian Journal of Civil Engineering, 38, 350-359.

Zhao, X. (2017). "A Scientometric Review of Global BIM Research: Analysis and Visualization." Automation in Construction, 80, 37-47.

Zolfagharian, S., and Irizarry, J. (2014). "Current Trends in Construction Site Layout Planning." Construction Research Congress, Georgia, 1723-1732. 